\title{
AVATARES: O MARAVILHOSO E O ESTRANHO NO SECOND LIFE ${ }^{1}$
}

Avatars: the wonderful and the weird at Second Life

Avatares: el maravilloso y extraño en Second Life

LAURA GRAZIELA GOMES ${ }^{*}$

DOI: http://dx.doi.org/10.1590/S2178-14942020000100010

'Universidade Federal Fluminense (UFF), Niterói (RJ), Brasil.

* Departamento de Antropologia (GAP/UFF). Programa de Pós-Graduação em Antropologia (lauragraziela@gmail.com). ORCID ID: http://orcid.org/0000-0002-0044-5259.

Artigo recebido em $1^{\circ}$ de agosto de 2019 e aprovado para publicação em 3 de dezembro de 2019. 


\section{RESUMO}

0 artigo tem como objetivo discutir o maravilhoso e o estranho no mundo virtual Second Life, bem como as relações de engajamento e de cuidados que os usuários humanos dispensam às suas criaturas, os avatares. Desde 2007, venho me dedicando a observar e a acompanhar o desenvolvimento desse mundo e seus modos de vida possíveis sob diferentes aspectos, bem como as premissas lógicas, simbólicas e subjetivas sobre as quais se desenvolve e se sustenta toda a existência, especialmente a economia desse mundo virtual, fazendo do Second Life uma das mais antigas e bem-sucedidas plataformas digitais imersivas conhecidas em funcionamento.

PALAVRAS-CHAVE: Second Life; Mundos virtuais; Avatares.

\section{ABSTRACT}

The article aims to discuss the wonderful and the strange in the Second Life virtual world, as well as the engagement and care relationships that human users bestow on their creatures, the avatars. Since 2007, I have been dedicating myself to observe and follow the development of this world and its possible ways of life in different aspects, as well as the logical, symbolic and subjective premises on which all existence develops and sustains, especially the economy of this virtual world, making Second Life one of the oldest and most successful digital platforms in operation.

KEYWORDS: Second Life; Virtual worlds; Avatars.

\section{RESUMEN}

El artículo tiene como objetivo discutir lo maravilloso y lo extraño en el mundo virtual Second Life, así como las relaciones de compromiso y cuidado que los usuarios (humanos) dedican a sus criaturas, los avatares. Desde 2007, me he dedicado a observar y seguir el desarrollo de este mundo y sus posibles formas de vida en diferentes aspectos, así como las premisas lógicas, simbólicas y subjetivas en las cuales se desarrolla y se sostiene toda la existencia, en especial la economía de este mundo virtual, haciendo de Second Life una de las plataformas digitales más antiguas y exitosas en funcionamiento.

PALABRAS CLAVE: Second Life; Mundos virtuales; Avatares. 


\section{INTRODUÇÃO}

0 Second Life, ou SL, como será chamado daqui por diante, foi criado em 2003 por Philip Rosedale' então CEO da empresa Linden Lab, sediada nos Estados Unidos. Com alguns intervalos de interrupção, desde 2007, tenho me dedicado a observar e a acompanhar o desenvolvimento desse mundo e de seus modos de vida possíveis sob diferentes ângulos. Destacarei aqui aquele que considero um dos mais importantes e pouco discutidos nos trabaIhos já publicados sobre o SL, a saber, o estatuto do maravilhoso e do estranho nesse mundo virtual, em grande parte propiciado pelos vínculos de amor e afeto (laços fortes) entre os usuários humanos e seus respectivos avatares, como condição necessária para as formas de imersividade e as relações de engajamento com esse mundo para que ele exista. Trata-se de um fato naturalizado, mas que considero relevante, para entendermos as premissas lógicas, simbólicas e subjetivas sobre as quais se desenvolve e se sustenta toda a existência nesse mundo, especialmente sua economia, fazendo dele uma das mais bem-sucedidas plataformas digitais imersivas conhecidas em funcionamento.

De fato, não por acaso, o SL tem um mito de origem que remete sua criação à possibilidade de seus usuários defrontarem-se com "monstros" e um ambiente "maravilhoso". Wagner James Au, ciberjornalista norte-americano que, desde 2003, dedica-se a escrever crônicas e reportagens sobre o SL em seu blog New world notes, $^{2}$ concedeu uma entrevista ao G1, publicada em 19 de março de 2008 por ocasião do lançamento no Brasil de seu livro Os bastidores do Second Life: notícias de um novo mundo, ${ }^{3}$ na qual narra como surgiu o SL.

Segundo Au, em 2002, a Linden Lab desenvolveu um projeto chamado Linden World, embora não soubesse muito bem o que fazer com ele. Uma primeira mudança importante do projeto em direção a seu produto final foi quando se enfatizou a liberdade de criação de conteúdo, deixando-o bem próximo daquilo com que Philip Rosedale sempre sonhara, isto é, criar um "lego virtual, onde você pode construir coisas — e até mesmo vendê-las". No entanto, isso ainda não era suficiente. Era preciso saber para que serviria exatamente esse mundo virtual. Au relata que um momento marcante foi quando

Eles [Linden Lab] receberam a visita de um grupo de investidores, que ficou assistindo aos funcionários usarem o programa. Em determinado momento, um deles criou um grande boneco de neve. De modo espontâneo, os outros usuários criaram versões pequenas do monstro e se ajoelharam em frente dele, começando a adorá-lo como se fosse um deus. Os investidores viram aquele esforço colaborativo e disseram: "É isso! É para isso que ele serve!" Foi nesse momento que o Second Life ganhou sua cara atual... 
Como em vários outros ambientes imersivos, para ingressar no SL, além de um equipamento 4 potente, é necessário um navegador próprio para acessar o sistema. Ao abrir sua conta e conectar-se pela primeira vez, o próprio usuário é apresentado a algumas opções de avatares genéricos para escolher uma delas, poder completar seu login e, finalmente, "nascer" naquele mundo. Esse "nascimento" implica a aparição do avatar escolhido do outro lado da tela e que, doravante, ficará vinculado ao perfil do usuário em caráter permanente. Assim, todas as vezes que se conectar ao SL, o usuário terá diante de si seu avatar, seu "outro", "do outro lado de lá" da tela, com o qual terá de estar conectado para poder fazer qualquer coisa "lá dentro" (do SL). Mas isso não é ainda suficiente, pois, em seguida ao nascimento, será preciso construir um vínculo forte com sua criatura, que se inicia com o processo de singularização do avatar, para modificar a aparência genérica dele (Gomes, 2015). Assim, em pouco tempo fica evidente que a maior parte das interações realizadas, conversas, conflitos e dramas não dizem respeito diretamente aos usuários humanos que estão do "lado de cá" da tela, mas, como observa Au, dizem respeito, sobretudo, às criaturas das quais eles dependerão para "estarem lá dentro" e com as quais esses humanos se ocuparão boa parte do tempo em que estiverem conectados.

Muito embora a conexão e a relação com os próprios avatares tendam a ser tratadas tecnicamente, com o passar do tempo é possível observar que essas relações entre humanos e seus próprios avatares apresentam algo "excedente", "enigmático", enfim, "prodigioso", de tal modo que acaba afetando/contagiando todas as demais interações feitas no SL. Mesmo se omitindo ou se negando o lado problemático dessa relação, esses "excedentes enigmáticos" não deixam de ser motivo de inquietação e acabam gerando muitos dramas, até mesmo conflitos, para os humanos implicados, muitos deles pela intensidade das emoções e afetos que passam a manter em relação a seus próprios avatares e aos demais avatares com os quais se envolvem a partir de seus avatares. Analisando melhor esses "sentimentos" e emoções, fica patente que eles não se devem somente à proeminência sociotécnica do avatar, mas também decorrem dos investimentos subjetivos feitos pelos usuários humanos sobre suas criaturas, o que acaba reafirmando a centralidade do avatar no sistema e na relação com os demais humanos pelo poder de agência que essas criaturas adquirem. De fato, uma vez lá dentro, 0 avatar impõe-se, pois é a partir dele que o usuário vê, escuta, existe e adapta-se àquele mundo, enfim, é amado ou rejeitado. Temos, então, uma criatura que não é uma imagem apenas. Além de ser uma plataforma 3D, o SL tem uma física própria, produzida por um motor de física chamado havoc, feito para jogos eletrônicos, que faz parte do sistema com o objetivo de simular a física newtoniana e os movimentos básicos dos objetos. ${ }^{5}$ Tal fato confere uma qualidade surreal muito grande, que impõe o caráter maravilhoso e prodigioso desse mundo, que pode ser também associado à magia toda vez que o usuário humano "se vê transportado" para o 
outro lado da tela, naquela criatura que se movimenta, anda, corre, pula, voa, ${ }^{6}$ cai, esbarra em outros objetos, ${ }^{7}$ conforme faz os movimentos com seu mouse.

Desse modo, na condição de residentes daquele mundo, nossa percepção é, obrigatoriamente, alterada, para que possamos "permanecer lá dentro", no sentido de podermos criar e experimentar outra realidade, relacionarmo-nos com nossas criaturas, criarmos conteúdos e objetos. Nesse caso, uma vez conectado a seu avatar, é fundamental o usuário desenvolver uma perspectiva êmica, para poder criar sua "outra" vida lá dentro. Esta, aliás, não precisa ter relação alguma de continuidade com sua vida real (doravante $\mathrm{RL}$ ). Chegamos, assim, a um ponto importante: podemos tomar o SL como um ambiente "intradiegético" (Meudal, 2005) e, ao nos depararmos com aquele ambiente "extraordinário", "maravilhoso", "prodigioso" e até "monstruoso" que se impõe a nós, precisaremos, tal como Alice (Carroll, 2010), ${ }^{8}$ aprender a lidar com sua lógica interna própria e assimilarmos e/ou construirmos a perspectiva daquela criatura estranha e muitas vezes bizarra, abdicando de nosso racionalismo humanista para nos deixar guiar pela criatura. ${ }^{9}$ Nesse sentido, todo residente do SL sabe, em alguma medida, que terá de flertar com o irracional para continuar sua aventura de conquistar, colonizar e habitar aquele mundo. Segundo Meudal, muitas vezes é preciso abrir mão de explicações e tomar esse mundo como óbvio. Só assim "uma coerência autêntica se instala entre a personagem e o novo universo onde essa evoluirá" (Meudal, 2005: 9). É esse acordo tácito que nos jogos, mas, sobretudo, nos mundos virtuais, estimula e facilita o engajamento entre humanos, avatares e plataformas. Caso esse engajamento não ocorra, nada acontece, e nenhum daqueles ambientes ou objetos passa a fazer sentido para o humano, que, nesse caso, não desenvolve interesse pelo ambiente e retira-se. Além disso, é preciso ter em mente que o SL tem uma economia própria. ${ }^{10}$ São números bastante significativos, sobretudo se entendermos que esse dinheiro e tempo gastos estão diretamente envolvidos com a existência dessas criaturas, com os cuidados a elas dispensados, correspondendo à criação de conteúdos e objetos destinados à manutenção dos avatares, visando a modificá-los, aperfeiçoá-los, singularizá-los. Gastos e atividades econômicas estão também diretamente relacionados com as formas de sociabilidade praticadas e desenvolvidas por meio e a pretexto dos avatares.

Diante do exposto, meu principal argumento é que a relação entre humanos e avatares no SL forma seres compósitos, híbridos, mas que não devem ser tratados como meros substitutos do usuário. Esse hibridismo deve-se ao componente sociotécnico, mas que ao mesmo tempo propicia uma existência material autônoma e própria, já que não deixa de ser um "outro", uma vez que se encontra localizado em um mundo que tem uma física alternativa, diferente daquela onde vive seu usuário humano. É importante destacar que essa relação híbrida de 
ambos não resulta em uma mistura coalescente. Enquanto está conectado ao SL, o humano encontra-se também conectado a seu avatar, humanizando-o, mas em troca também sofre as agências deste e daquele ambiente, sendo, portanto, "avatarizado" por sua criatura. Contudo, ao se desconectarem, ambos se separam, ainda que o humano possa manter-se intensamente afetado. Esse é um aspecto fundamental e, ao mesmo tempo, "inquietante" desse híbrido, dessa forma de conexão e relação, que não pode ser naturalizada. Nesse sentido, enquanto estão conectados, o avatar também não se torna uma simples extensão, ou repetição, do self de seu humano, da mesma forma que aquilo que o humano vai viver e experimentar junto com seu avatar não terá continuidade em sua vida real, embora possa afetá-la por sua subjetividade. De todo modo, as relações do usuário consigo mesmo, estando conectado ou não a seu avatar, não serão as mesmas. São afecções distintas, aquela que se leva para a RL na forma de memória, qualidade da experiência e aquela outra que faz parte do engajamento no aqui e agora com o avatar, naquele mundo, durante a imersão. Finalmente, a qualidade da experiência das imersões não se repete jamais, não é estável ou coerente, muito menos 0 humano dominará/controlará totalmente sua criatura e aquele mundo. Como na vida offline, há situações únicas, inesperadas, mas as imersões não se sucedem na mesma escala e ritmo da temporalidade da vida offline. De meu ponto de vista e de meus interlocutores com quem pude conversar ao longo do tempo a respeito das relações com seus avatares, o que se impõe nessa relação é justamente a "estranheza", a diferença, uma vez que cada imersão é distinta das demais, em todos os sentidos. Assim, a questão de "quem controla quem na relação de engajamento e conexão", seja entre humanos, a máquina, o sistema e o próprio avatar, é muito variável. De toda forma, o híbrido formado pelo humano e seu avatar apresenta outra situação que merece ser destacada e também constitui um dos elementos da estranheza, pelo fato de o avatar apresentar uma resiliência própria em razão de sua natureza maquínica, mas que surpreende muitas vezes esse humano por causa dos investimentos afetivos realizados sobre a criatura. É como se fosse uma traição. Quando se imagina que o avatar está completamente domesticado, eis que ele surpreende seu humano. Esse lado não previsível para o usuário humano pode ser pensado como um enigma, e a ele caberá, "do lado de cá" da tela, o trabalho de decifrar.

Outra questão que se impõe é sobre o próprio desenvolvimento do trabalho de campo em um ambiente como esse. Enquanto as redes sociais reforçam o que Ramos (2015: 59-75) identificou como "convergência identitária", isto é, uma continuidade entre a vida civil offline e o perfil online dos usuários, tal não ocorre necessariamente em ambientes imersivos. No caso dos games, é até possível jogadores apresentarem-se em redes sociais e fóruns com seu apelido de jogador ou de seus "personagens". Entretanto, no SL a identidade civil, ou RL, é, 
por princípio, mantida em total anonimato no SL, prevalecendo a "divergência identitária". Nada obriga um avatar dar a conhecer em seu perfil a identidade de seu usuário humano, bem como informações sobre sua vida offline ou $\mathrm{RL}$, mesmo para um pesquisador. Da mesma forma, usuários podem vetar a divulgação para fora do SL de imagens de seus avatares, ou ainda, tal como ocorre nas pesquisas de campo offline, presenciais, podem exigir que os nomes de seus avatares não sejam divulgados para fora do SL. O mesmo pode ser dito do que é conversado em chats privados ou mesmo em chats públicos do SL, que não devem ser reproduzidos para fora do SL sem autorização dos residentes. A Linden Lab tem como política proteger completamente o direito ao anonimato de seus usuários, e somente ela tem acesso às informações e às suas identidades civis. Nesses termos, toda a minha pesquisa de campo vem sendo realizada respeitando essas regras. Em todo esse tempo, mantive contatos fora do SL apenas com interlocutores que se dispuseram a isso, por livre e espontânea vontade. Nesse caso, meu trabalho de campo tem a peculiaridade ou a estranheza de ter sido feito somente com e entre avatares no SL, sem conhecer as identidades das pessoas dos usuários, o que implicou observação participante, já que, para "entrar lá", precisei permanecer conectada a um avatar que também desenvolveu uma reputação social dentro do mundo, teve uma vida social e foi identificado como residente daquele mundo. Só assim, interagindo no mundo como "nativa" (residente), pude realizar minhas observações, manter conversações no chat, fazer registros fotográficos e audiovisuais de situações que considerei relevantes para poder explorar futuramente em artigos. Isso significa dizer que todas as situações registradas e descritas por mim foram observadas e testemunhadas durante minhas imersões com meu próprio avatar. Disso resulta que nunca foi meu objetivo conversar sobre suas vidas offline para compará-las com suas vidas no SL, porque uma de minhas premissas metodológicas, desde o início, foi entender o SL a partir de seus próprios termos, enfatizar esse investimento subjetivo na "divergência identitária" daqueles que lá vivem com suas criaturas e seus modos de habitar aquele mundo, salvo quando eles tomavam a iniciativa de fazê-lo, Quando alguns quiseram falar comigo sobre suas vidas e identidades $\mathrm{RL}$, não me recusei, mas tal fato não constituiu 0 foco de minha atenção. Finalmente, todos os interlocutores e residentes com os quais interagi sabem que sou antropóloga e pesquiso aquele ambiente.

Como afirmei antes, o avatar - e não o usuário - é que tem proeminência no SL, e, para tanto, ele precisa despertar o interesse dos demais, o que inclui uma relação de muitos cuidados, afeto e amor. Como observou Au (2008), trata-se de um vínculo que depende de "dedicação e devoção" dos humanos em relação a seus avatares. Os atributos necessários para ser famoso, além de atraente, ter carisma e causar forte impressão nos demais. É esse 
detalhe que confere toda singularidade à "segunda vida", tornando-a complexa e com muitos incidentes de percurso. Portanto, a "estranheza" da situação não está apenas na criatura em si, mas no fato de que, embora inicialmente ela não faça parte de nós e seja exterior a nós, acaba por tornar-se um duplo, sem se confundir ou se misturar totalmente conosco, mas nos "encantando" e nos "enfeitiçando", conforme argumenta Alfred Gell (2005) ${ }^{11}$ em seu ensaio "A tecnologia do encanto e o encanto da tecnologia" quando "propõe que a antropologia da arte considere a arte um componente da tecnologia, e seu produto, resultado de um arranjo de técnicas - o conjunto de todas as artes formando a tecnologia do encanto".

\section{O RETORNO DO "MARAVILHOSO" E SUA EFICÁCIA SIMBÓLICA}

$A_{\text {gioso" }}$ gue discutiram a questão do "maravilhoso", " estranho", " inquietante", " prodiNada existe nesse sentido sobre o caráter ambíguo dos "avatares" no SL, ou dirigido ao contexto contemporâneo das plataformas digitais, especialmente as imersivas, como parte de sua lógica e eficácia simbólica. Em meu caso, tal aproximação partiu da compreensão de que, afinal, "estranho" e "familiar", dois termos aparentemente opostos, estão, na verdade, interligados (Freud, 2010), o que, para mim, é importante, tendo em vista alguns desdobramentos testemunhados por mim no SL. Não entrarei nessa discussão neste artigo, mas plataformas imersivas e interativas são diferentes e têm objetivos também diferentes no que se refere às influências que exercem sobre a modelagem da realidade social. Assim, enquanto plataformas digitais interativas tendem a ser desenvolvidas para uso massivo, as imersivas são desenvolvidas para nichos de usuários específicos, voltadas para propiciar e estimular habilidades diferentes em seus usuários. Isso explica meu objetivo de investigar as plataformas imersivas e sustentar que a divergência identitária, ou o processo de dividuação (Gomes \& Leitão, 2011)12 é um investimento feito também pelos desenvolvedores de games e mundos virtuais, e não um acontecimento casual ou investimento e interesse somente do usuário, apesar de que este tem papel fundamental, como explicarei mais adiante.

Em um artigo, Nodari (2015) destacou a presença da obliquação na escrita de Clarice Lispector. Em meu caso, argumento que a tecnologia digital vem cada vez mais proporcionando essas experimentações de si, ou formas de tergiversações de si em um caminho traçado, que se imagina controlado, mas que, de acordo com Rose (2011), vai formando "dobras" ou "pregas" nas subjetividades. Tal fato pode parecer contraditório, caso apliquemos a noção de

"estranho" exclusivamente ao campo dos eventos extraordinários apenas. Na maior parte das vezes, é somente quando classificamos o estranho como alteridade radical que conseguimos 
aceitar a estranheza. Contudo, tanto na tradição ocidental quanto em muitas outras, não é incomum as narrativas míticas e literárias recorrerem ao insólito e apresentarem-no junto com o familiar, dois termos aparentemente contraditórios, mas interligados, ao mesmo tempo que tratam do tema da metamorfose. Na literatura ocidental, tanto a mitologia/literatura clássica quanto as narrativas medievais, a literatura romântica (gótica) e a cultura de massas mostram-nos seres e criaturas "maravilhosas" e "monstruosas", ao mesmo tempo que narram as relações de proximidade estabelecidas por elas com indivíduos humanos ou grupos humanos inteiros. Mais ainda, conhecemos muitas narrativas que dão ênfase às relações de afinidade e/ ou de parentesco, ou mesmo de extrema familiaridade (muitas vezes de intimidade), estabelecidas entre esses "seres maravilhosos" e os humanos.

Entretanto, essas estranhezas podem ocorrer sem grandes alardes, mas de forma insidiosa, porém não menos contundente, como afirma Nodari em relação à escrita de Clarice Lispector. Como afirmei anteriormente, o SL, para existir, depende do engajamento de seus usuários com os avatares para que a plataforma exista. Disse também que, no caso do SL, o acesso a essa plataforma é assimilada a um deslocamento, muitas vezes percebido pelos usuários como uma viagem e até mesmo uma forma de migração, próximo ao que Ghassan Hage (2005: 470) chama de "mobilidade existencial": "We do not engage in existential mobility in order to experience physical mobility. The contrary is true: we engage in the kind of physical mobility that defines us as migrants because we feel another geographical space is a better launching pad for our existential selves." 13 Nesse caso, é possivel dizer que o "deslocamento" não é necessariamente físico, mas se apresenta na forma de um deslizamento subjetivo, que é percebido por todos os usuários. Foucault (1984) escreveu sobre esse outro sentido dos deslocamentos quando falou das heterotopias. Para ele, a noção de "lugar" recobre também os espaços e ambientes com outros sentidos, sentimentos e experiências, como refúgio, conforto, acolhimento, segurança e liberdade. Para o SL, tornar-se um lugar para onde se deseja ir continuamente, o engajamento e os vínculos formados pelas relações de devoção e amor do usuário por seu avatar é a condição necessária; quanto mais esse amor realiza-se, mais aumenta o interesse pelo ambiente, fazendo com que a relação com suas criaturas aumente igualmente o desejo de nele permanecer e dedicar grande parte de seu tempo criando e construindo objetos dentro desse mundo, povoando-o de coisas igualmente maravilhosas, que estão igualmente impregnadas de subjetividade, memórias, já que todos os objetos trazem consigo a marca de seus criadores (Gomes, 2015). Portanto, quanto mais cuidada, maiores são o apego e 0 interesse pela criatura, da mesma forma que mais possibilidade de ela criatura poder afetar bastante seu dono e por meio deste criar coisas que, de muitos modos, afeta e, assim, faz com que outros se afetem, constituindo uma communitas imaginária baseada na divergência 
identitária, ambiguidade e liminaridade subjetivas, isto é, nas formas de obliquação que levam e estimulam novas percepções de si naquele ambiente.

Diante do exposto, creio que torna mais fácil entender a razão pela qual a Linden Lab aposta nessa divergência: ela é a razão de toda a economia do SL. Ao contrário dos games, o SL não tem missões ou objetivos a serem cumpridos e não tem mapas e gráficos criados pela empresa desenvolvedora. Todos os ambientes por onde se circula nesse mundo são resultado do trabalho criativo de seus residentes (acessar link para o vídeo na nota 1). Além disso, as condições para que eles sejam criados e produzidos exigem muita dedicação e tempo de imersão, além de muitas competências em diferentes domínios do design gráfico, o que supõe saber usar softwares de edição de imagens (Photoshop e similares), softwares de modelagem de objetos em 3D, conhecimentos específicos de programação para fazer scripts, além de saber lidar com as próprias ferramentas do sistema para fabricação de determinados objetos e materiais, como a terraplanagem de um terreno, por exemplo. Trabalha-se muito para que esse mundo virtual tenha tudo o que nele existe. A expansão do SL nesses 16 anos de existência é prova disso. De algumas poucas ilhas, em 2003, hoje o SL é equivalente, em pixels e prims, ao tamanho de Manhattan, apresentando uma concentração equivalente de avatares e os mais variados objetos de diferentes procedências, como a grande metrópole. Não é pouca coisa para apenas 16 anos de existência, se imaginarmos que, em 2003, não existia quase nada, como destacou Au. São milhares e milhares de "ilhas", ${ }^{14}$ onde o residente encontrará tudo de que precisa para viver junto à sua criatura, da maneira como quiser, e ainda podendo criar cada vez mais conteúdos para si, para vender e/ou doar.

Assim, criação e construção de objetos constituem-se na atividade principal dos residentes, começando pela singularização do avatar. Em muitos momentos de meu trabalho de campo, pude acompanhar diferentes processos criativos naquele mundo, desde a criação de criaturas específicas e um modo de vida para elas, mas também a criação de uma variedade enorme de objetos. Certa vez, morei próximo a uma ilha habitada por sereias. Grande parte da ilha era submersa, para formar o ambiente propriamente marinho onde elas habitavam. Tudo foi construído pelos próprios residentes sereístas. Avatares que não fossem sereias podiam visitar a ilha, mas precisavam anexar caudas fornecidas pelos nativos para circular no ambiente. Não havia chances de andar nele com pernas. Em meu caso, classifiquei o ambiente com uma "instalação", porém essa não era a percepção daqueles que ali viviam. Perguntei a um avatar sereia como ele se sentia performando uma sereia, e a resposta foi imediata: "Mas eu sou uma sereia." Olhei para ela e tive de concordar: "Sim, você é uma sereia." 
Como observa Au, boa parte do tempo em que se está imerso é dedicado aos vários rituais de cuidados, que envolvem muitas manipulações, sendo o objetivo as modificações da aparência do avatar, ao mesmo tempo que se fica junto e conectado a ele, "interagindo" 15 com ele no ambiente e junto aos demais avatares, e isso inclui explorar o mundo com ele, fazer coisas com ele, para ele e os demais. Nesse sentido, a exibição e a interação do avatar em "lugares públicos" dentro do SL, frequentados por outros avatares, são de suma importância para que ele seja visto pelos demais (já que é necessário ver e ser visto), mas também para poder exibir suas habilidades, como foi o caso da ilha das sereias. Além de o ambiente marinho ter sido criado pelo grupo, cada uma das sereias era totalmente singularizada. Essa sucessão de cuidados, criações, exibições, performances e interações é o que chamo processo de enraizamento na plataforma, mas que só é possível a partir do engajamento do humano com seu avatar, de forma que este possa desenvolver uma biografia social (Appadurai, 2008). Quanto mais o avatar circula, quanto mais se torna visível no mundo, quanto mais cria conteúdos e interage, maior será sua reputação social e, portanto, maior será sua popularidade e seu mana (Mauss, 1974). Ora, não é possível tratar essa experiência como algo puramente utilitário, técnico, ou mesmo uma forma menor de entretenimento. Ao contrário, para que tudo ocorra de acordo com as expectativas desejadas, e as recompensas imaginárias e simbólicas ocorram, a socialização na lógica desse mundo, bem como com as ferramentas do sistema, torna-se fundamental. Nada disso ocorre sem essa singularização, e o avatar será identificado apenas como um noob (novato), podendo ser evitado pelos demais. Como no caso das sereias, os cuidados implicam modificações corporais que exigem um sentido e projeto estético combinados à habilidade técnica, para fazer o que se deseja, na busca de um resultado satisfatório e gratificante. Para tanto, além das manipulações corporais no avatar, existem vários acessórios fundamentais, capazes de tornar essa criatura compósita "maravilhosa" (mirabilia), que vão desde as formas corporais, como shapes, skins, cabelos, olhos, roupas, movimentos e gestos, que serão conectados ao avatar, até o próprio ambiente onde ele vai viver no SL, como acidentes geográficos, praias, rochas, montanhas, pedras, terra, flora e fauna, casas e prédios os mais diversos. ${ }^{16}$ Como é possível perceber, todo esse processo de singularização implica investimentos na ordem da produção de bens e serviços, levando a uma relação de devoção, sem a qual a eficácia simbólica da relação entre humanos e avatares inexiste, tampouco o próprio mundo. Nesse sentido, o avatar é um fetiche e um ídolo, e não exatamente um ícone do usuário. Portanto, trata-se de uma criatura excessiva, que ostenta algo para além de ser a metáfora de seu dono, algo que pode produzir estranheza.

Dito isso, todo residente do SL é profundamente afetado pelas relações que mantém com seus avatares, com os quais experimenta múltiplas experiências de si, possibilidades de obli- 
quação, metamorfoses e dividuações. ${ }^{17}$ É o "estar afetado" que se torna a condição necessária para o humano adquirir a perspectiva êmica da plataforma, de forma a sentir-se nativo e ter seu pertencimento reconhecido pelos demais em termos intradiegéticos, como coautor da trajetória de seu avatar, narrador e coadjuvante da própria personagem naquele mundo. Disso dependem a expansão desse ambiente digital e a própria experiência de imersividade de seus habitantes.

É importante destacar ainda que a aquisição dessa perspectiva êmica só é possível se vier acompanhada da continuidade dessa experiência imersiva, isto é, não apenas o tempo investido, mas a qualidade da experiência dessas imersões para que deixe de ser meramente um espectador (visitante) e torne-se verdadeiramente um residente. Ser residente é, assim, permitir deixar-se "ficar e permanecer afetado" pelo avatar e converter-se, subjetivamente, a essa condição de "metamorfose ambulante" por meio dele e naquele mundo, de tal forma que a estranheza de toda a situação transforme-se em algo familiar — não necessariamente naturalizado, mas conscientemente assumido como tal. Essa afirmação é fundamental, porque, quando me refiro aos aspectos "monstruosos", "maravilhosos", "prodigiosos" e "estranhos" que essas criaturas e relações de engajamento com elas apresentam e propiciam, não estou me atendo somente às formas dos avatares, por mais bizarras que sejam e por mais que reconheça a agência delas nessa relação, mas, sim, que esse processo de dividuação pode ser bastante ampliado, quanto mais o usuário dedicar seu tempo àquele mundo. É nesse momento que retomo a narrativa apresentada por Wagner James Au a propósito dos investidores observando os Lindens fazerem seus pequenos bonecos de neve ajoelharem-se e "adorarem" o boneco de neve maior, um "monstro", segundo suas próprias palavras, para rememorar um pouco a história da antropologia, da literatura ocidental e da psicanálise.

Em "Esboço de uma teoria geral da magia", Marcel Mauss (1974) buscou distinguir os fatos mágicos de outros fatos sociais com os quais costumam ser confundidos — os atos jurídicos, as técnicas e os ritos religiosos. Para o autor, fatos mágicos seriam fatos da tradição, portanto atos que se repetem, que são transmissíveis, sendo as práticas mágicas "sancionadas pela opinião" e de forma alguma "atos estritamente individuais, como as práticas supersticiosas dos jogadores" (Mauss, 1974: 48). Ao destacar as relações entre magia e técnica, Mauss chamou a atenção também para o fato de que ambas são "criativas", por envolverem gestos, procedimentos que precisam ser corretamente desempenhados, a fim de obterem a eficácia desejada, não apenas simbólica, mas também prática e material. Elas tomam, muitas vezes, a forma de um artefato ou de procedimentos físicos que têm como objetivo intervir na natureza para lhe produzir uma mudança de estado, como ocorre, por exemplo, com as técnicas agrícolas. Para Mauss (1974: 49), " a série de gestos do artesão é tão uniformemente regulada quanto a série de gestos do mágico", e é nesse sentido que técnica e magia muitas vezes são confundidas. 
Segundo Kappler (1994), a Idade Média forneceu-nos um exemplo no âmbito da própria cultura europeia a respeito de como o cristianismo, ao desenvolver uma desconfiança em relação às técnicas e aos conhecimentos antigos (pré-cristãos), confundiu a magia com a heresia. 0 fato de a repetição de certos gestos ou procedimentos ser eficaz em certos domínios, isto é, ter uma relação de causalidade previsível e bem-sucedida, passou a ser suspeito de ser feitiçaria, portanto heresia, apostasia, tanto no âmbito da produção artesanal quanto no das práticas de cura. Um exemplo disso foi a relação direta estabelecida pela Igreja entre o uso terapêutico de infusões preparadas à base de plantas e ervas e a cura de certas doenças com a magia. Até então, tratava-se de um saber tradicional, sancionado coletivamente pelas sociedades pré-cristãs da Europa. 0 fato de tais saberes serem profundamente enraizados e transmissíveis constituía a base de sua própria autoridade. Nesse sentido, a Inquisição não foi apenas o combate aos infiéis, mas, sobretudo, um dispositivo jurídico e político criado para desautorizar e destruir todo esse patrimônio cultural, em grande medida preservado pela população não letrada, por meio da repetição ritualizada de saberes técnicos e práticos.

Do ponto de vista deste artigo, o "Esboço de uma teoria geral da magia" (Mauss, 1974) mostra como no SL existe um conjunto de saberes sancionados coletivamente a respeito de certas técnicas que o usuário deve aprender antes de pretender tornar-se um desenvolvedor de conteúdo, dar sua contribuição a partir de suas habilidades próprias. Um exemplo é o conhecimento básico de editar o shape do próprio avatar para que sua aparência fique melhor, dependendo da skin ou da roupa. É uma técnica que se aprende desde que se entra no SL, e, apesar de básica, pode surpreender com os efeitos que proporciona. A aquisição e a transmissão desse saber ou expertise (técnica) mesmo de ordem prática têm sido fundamentais para a construção daquele mundo, algo que não se confunde com um saber formal, mas que se refere a um saber prático, que todos os usuários da plataforma precisam saber e compartilhar para poderem acessar o SL, conectarem-se às suas criaturas e manipularem os objetos. 0 fato mesmo de não considerarmos nossos avatares um bem ou um serviço é um pressuposto do engajamento afetivo com a máquina e com a própria rede, fator primordial para termos acesso às experiências naquele mundo e entrarmos em sintonia com eles. Se é assim, o deslocamento supõe a desistência e a renúncia aos pressupostos lógicos que estão na base da ciência da computação, para deixar prevalecer o pensamento mágico e tudo o que é característico dele, como a bricolagem, formas de associação e participação — além daquele sentimento de sintonia profunda — com os fenômenos maquínicos, como sendo parte deles. De fato, é interessante observar que o engajamento com a tecnologia digital, para além do uso tecnológico e formal, é responsável por uma subcultura cujo imaginário está estreitamente vinculado ao pensamento mágico. Tal imaginário é bastante visível nos ambientes imersivos, nos games e 
nos mundos virtuais, nos quais, sobretudo, retoma-se o maravilhoso, não apenas como parte de uma aparência visual, ou paisagem, mas como parte da experiência de "estar lá", isto é, de "ser" e de se fazer as coisas "ali dentro", de se tomar a técnica em outros termos. Como já observado no caso do SL, embora o avatar seja um objeto técnico produzido pelo próprio sistema da plataforma, ao ser manipulado de muitas maneiras, as combinações podem ser infinitas, podendo produzir efeitos os mais diversos, do ponto de vista seja negativo — inquietação, estranheza, alteridade — seja positivo — maravilhamento, encantamento, paixão, amor etc. A arte de fazer um avatar e de torná-lo interessante, belo, original, bizarro ou horripilante exige manipulações técnicas que, no entanto, não são percebidas sempre como tais, mas como atos mágicos, que podem ser repetíveis e transmissíveis.

Nesse sentido, importa dizer que a monstruosidade não incide apenas sobre as aparências e formas naquele mundo. Para Corrado Bologna (1997), no mundo greco-romano, o "monstro" foi, sobretudo, relacionado com o enigma (ainigma), isto é, a uma forma de saber considerada prodigiosa, diretamente proveniente da origem dos tempos, mas também relacionada com o devir, os novos tempos que virão. Nesse sentido, o "monstro" é aquela criatura que "mostra", "apresenta" uma verdade, faz uma revelação ou aponta um "problema", dá a conhecer algo importante por meio de um enigma que deverá ser resolvido (interpretado), para se chegar ao conhecimento desejado.

Ainda em relação ao "monstro", cabe considerar que, do ponto de vista da aparência, ele nem sempre esteve associado à feiura, ao medonho (àquilo que inspira medo e terror). Ao contrário, na Odisseia, Ulisses precisa tapar seus ouvidos para não se deixar seduzir pelo canto suave das sereias, elas próprias percebidas como "seres maravilhosos", belas, sedutoras, parte mulheres, parte peixes ou pássaros. No pensamento grego antigo, a Esfinge é um monstro que representa de forma emblemática o teras - a maravilha e o monstro em termos de criatura compósita, em uma escala de grandeza muito elevada — em sua relação com o enigma, a verdade e o conhecimento (profético), especialmente no que se refere à condição humana. No entanto, como se verá no mito de Édipo, trata-se de uma verdade que não é transparente ou não se dá a revelar imediatamente, mas que necessita de um intermediário, representado pela atitude hermenêutica de Tirésias, o velho sábio.

Apoiando-se nos ensaios de Emile Benveniste, Bologna argumenta ainda que, de todos os termos teratológicos latinos, como miraculum, omen, monstrum, ostentum, portentum, prodigium, somente a palavra monstrum adquiriu uma especialização, perdendo a conotação originária de mostrare algo ou fenômeno que pretende "ensinar uma conduta, prescrever a via a seguir" (Bologna, 1997: 321). Contudo, embora tenha decaído, tenha sido jogado 
aos infernos ou reduzido a um fóssil do pensamento, o monstrum não foi extinto. Como personagem literária e figura de retórica, ele permaneceu, continuando a jogar luzes em direção aos recônditos da imaginação. 0 advento de uma cultura audiovisual de massas, bem como da literatura também de massas, na esteira de um processo de mudanças sociotécnicas, trouxe-o de volta à vida como alegoria e mesmo como fato social onipresente, parte da própria realidade, conforme escreveu Donna Haraway (2000) a respeito dos ciborgues e (Latour, 2012) a respeito dos híbridos, agentes e agenciamentos em sua teoria TAR. Nesse sentido, falar do avatar como monstrum não é, de forma alguma, pretender reduzi-lo à sua aparência ou mesmo à negatividade, mas, sim, por meio de uma pesquisa atenta acerca de seu campo semântico, retomar seu sentido original de "mostrar algo", "apresentar algo" que até então não estava devidamente revelado ou explicitado, por exemplo, a própria condição híbrida do sujeito contemporâneo. De acordo com Haraway (2000: 36), "o ciborgue é um organismo cibernético, um híbrido de máquina e organismo, uma criatura de realidade social e também uma criatura de ficção".

Paralelamente à percepção do avatar como monstrum e ciborgue, torna-se necessário dar conta do próprio significado do termo avatar e de seu uso corrente na cultura digital, especialmente em ambientes imersivos. Esse uso não elimina a ideia do "maravilhoso", do "prodígio", tampouco a noção original do termo: uma forma encarnada, uma manifestação corporal de um deus. Entretanto, há de se considerar a hipótese de que exista uma diferença de significado entre monstrum e avatar, conforme o híbrido formado. Assim, enquanto no avatar prevaleceria a noção de uma representação icônica, uma "encarnação ou substituto do usuário" naquele mundo, entendida de forma totalizada, o monstrum diz respeito a uma relação mais complexa, na medida em que já implica a desconstrução dessa representação icônica, não fraturada. Insisto em afirmar que, quanto mais o usuário singulariza seu avatar, ele se torna um residente mais experiente e, como consequência, passa a ter mais de um avatar, com os quais mantém relações diferentes, em que cada avatar "encarnaria" ou se "especializaria" em uma das muitas dobras subjetivas do usuário humano, algo que nos remete à noção de heterônimos. É nesse contexto que as experiências nesses mundos tendem a ser percebidas como "maravilhosas", "prodigiosas", imaginativamente mais densas.

Dito isso, meu argumento é que, por causa dessas transformações e surpresas, o avatar nunca é uma mimese estável e segura do usuário humano real, mas uma mimese precária e provisória de nossas idealizações, demonstrando o quanto nossa subjetividade é um devir constante que colapsa a própria ideia de uma identidade igualmente estável e coerente. Assim, o caráter mimético reside justamente naquilo que pode parecer ao usuário como sendo 
seu lado mais estranho e surpreendente, a ponto de desestabilizá-lo, não porque ele vê diante de si uma criatura compatível com as aspirações e representações que faz de si próprio na $\mathrm{RL}$, mas como uma transposição de seus desejos, fantasias e até mesmo seus fantasmas mais angustiantes. Nesses casos, o "amor" e os vínculos estabelecidos entre o usuário e seus avatares não são produzidos exclusivamente pela semelhança, pelo que já é conhecido por ele a respeito de si, mas pelo fato de ser surpreendido pela constatação da diferença que emerge a partir de imagens ou percepções dissidentes de si. A surpresa reside, então, no fato de o usuário deparar-se com uma versão digital de si ou de outra criatura avatar que pode encarnar ou deixar evidente algo que habita seus sonhos, suas fantasias, seus medos e pesadelos. Esses eventos recorrentes são responsáveis não apenas por várias "baixas" (saídas do SL), mas afetam profundamente e de muitas formas os usuários que ali permanecem. Em geral, eles não são inicialmente percebidos como normais, mas, sim, como eventos "estranhos" e "singulares", "mágicos", "extraordinários". Dependendo dos usuários envolvidos, podem produzir tanto um sentimento de inquietação, angústia quanto de prazer e realização. No primeiro caso, como já assinalado, muitas pessoas desistem do ambiente, e seu discurso invariavelmente deixa transparecer o mal-estar por não terem conseguido entender-se com a "estranheza" daquele mundo e do avatar, muitas vezes culminando em uma série de acusações ao ambiente virtual. Segundo Anne-Marie Meudal (2005), não por acaso a "maravilha" e 0 ato de "maravilhar-se" remetem ao vocábulo latino mirabilia (do verbo mirari, que significa "ver"), da mesma forma que o termo remete a algum tipo de

[...] conflito entre a percepção das coisas e sua compreensão, mas são além disso frequentemente marcadas por uma ambiguidade inquietante: como saber se trata-se de uma manifestação do bem ou do mal? Para compreendermos, é necessário recordar que o imaginário com frequência recorreu ao corpo.

Essa citação faz lembrar alguns exemplos literários de metamorfoses em que o corpo assume um lugar central na produção da ambiguidade e da inquietação. Temos o exemplo da novela escrita por Robert Louis Stevenson, em 1876, intitulada The strange case of Dr. Jekyll and Mr. Hyde, conhecida em português como $O$ médico e o monstro (Stevenson, 2012). Na história, a personagem Richard Enfield narra a um amigo, o advogado Utterson, as desventuras do dr. Jekyll, um médico londrino que, após inventar uma fórmula em seu laboratório particular e experimentá-la em si mesmo, passa a ter um "segundo eu" e uma "segunda vida", ambos secretos, por meio de uma criatura medonha que irrompe de suas entranhas. Outro caso igualmente conhecido é a novela de Franz Kafka (1998) A metamorfose, cuja introdução produz uma profunda inquietação no leitor por conta da forma como o autor introduz o tema 
da metamorfose ou da repetição e da diferença, para usar uma referência a Deleuze (1988), ao afirmar que a diferença sobrepõe-se à mesmidade/identidade, embora ambas andem de mãos dadas. Assim, Gregor Sansa, em "uma manhã, ao despertar de sonhos inquietantes, [...] deu por si na cama transformado num gigantesco inseto" (Kafka, 1998). Estranhamente, Gregor, em vez de ficar apavorado, passa a tecer considerações prosaicas sobre sua condição. A cultura de massas contemporânea também utiliza à exaustão esse jogo de repetição/ diferença com os "super-heróis" que habitam o interior dos mesmos personagens aparentemente comuns, ordinary people (identidade, mesmice). Essa criatura extraordinária, dotada de superpoderes, não raro surge mediante algum incidente. É recorrente o tema do laboratório, das experiências técnico-científicas "malsucedidas" que produzem efeitos de mutação e metamorfose. Uma versão relativamente recente, inspirada na novela de Stevenson, é a personagem dos quadrinhos 0 incrível Hulk, uma gigantesca criatura verde (Gigante Esmeralda) que jaz escondida nas células atingidas pelos raios gama do corpo do cientista dr. Robert Bruce Banner. Diferentemente de seu sucedâneo vitoriano, Hulk é um pouco menos maniqueísta, mais contraditório e fraturado. Toda vez que Banner fica colérico, o que é bastante comum, a criatura reorganiza-se no interior de seu corpo e irrompe para o mundo. Quanto mais cólera sente, mais poderoso Hulk torna-se. Eis o enigma de Banner. Em todos os casos ilustrados, o "estranho" apresenta-se realmente como "aquilo que se afasta do curso ordinário das coisas" (Meudal, 2005), embora, como afirma Deleuze, ande lado a lado com a mesmice e, finalmente, de acordo com Freud, faça parte da própria noção de familiar (unheimlich e heimlich).

Em seu artigo intitulado "O inquietante", Freud (2010) apresenta subsídios para seguir adiante na compreensão das experiências que procuro narrar e discutir neste trabalho, permitindo-me fazer ainda uma conexão com a psicanálise e com a filosofia (Deleuze). Segundo Freud, a palavra "estranho", em alemão, é "unheimlich", e seu oposto é "heimlich" ("doméstico"). Citando Jentsch, Freud observa que este atribuiu à incerteza intelectual o fator essencial para a origem do sentimento de estranheza: "Quanto melhor a pessoa se orientar em seu ambiente, mais dificilmente terá a impressão de algo inquietante nas coisas e eventos dele" (Freud, 2010: 200). Essa citação adquire especial importância quando pensamos nas experiências imersivas em mundos virtuais, ou mesmo nos games. De modo geral, quando ingressamos pela primeira vez nesses ambientes — pelo menos aqueles que o fizeram em uma idade mais adulta — , ainda não estamos suficientemente orientados. Não por acaso, utiliza-se a expressão "nascer", da mesma forma que a categoria noob, para designar todos aqueles que são recém-chegados. Em uma primeira aproximação, os mundos virtuais apresentam-se povoados por situações inquietantes e, como destaca Freud, seres ambíguos, que nos fazem experimentar ideias e sentimentos contraditórios, pois, ao mesmo tempo que nos 
causam estranheza, tornam-se, por questões sociotécnicas, nossos "companheiros" e afins mais próximos, com os quais teremos de nos conectar, interagir e desenvolver relações de familiaridade, de afinidade, de colaboração e de intimidade. Portanto, trata-se de criaturas e objetos inquietantes e estranhos - em todos os sentidos - que terão de tornar-se próximos, familiares, íntimos, para que possamos frequentar, colonizar e habitar aquele ambiente.

Prosseguindo em sua análise, Freud chega ao ponto que nos interessa para este trabalho. Novamente citando Jentsch, faz referência às situações mencionadas pelo autor, capazes de "despertar em nós um sentimento de estranheza". Jentsch aborda os contos de Hoffmann e os artifícios por ele utilizados, capazes de deixar seu leitor na incerteza "de que determinada figura seja uma pessoa ou um autômato, e isso de modo que tal incerteza não ocupe o centro da sua atenção, para que ele não seja induzido a investigar a questão e esclarecê-la, pois assim desapareceria o peculiar efeito emocional", como foi dito. Em um desses contos de Hoffmann, "The Sand Man" (O homem da areia) conta a história de um homem que roubava os olhos das pessoas. Ao destacar os pontos altos dessa narrativa, Freud descreve o amor que Nathaniel, protagonista do conto, desenvolve, em dado momento, por uma boneca chamada Olímpia ${ }^{18}$, que parece ter vida. Segundo Freud, Jentsch acreditava que sentimentos de estranheza existem

[... quando há uma incerteza intelectual quanto a um objeto ter ou não vida [...] bonecas são intimamente ligadas com a vida infantil. [...] de modo algum as crianças distinguem nitidamente objetos vivos de objetos inanimados, e gostam particularmente de tratar as suas bonecas como pessoas vivas. (Freud, 2010: 2006)

Não é preciso dizer que avatares podem ser incluídos na categoria dos objetos e das criaturas citadas. Não deixam de ser autômatos digitais, mas, dada a tecnologia, a qualidade gráfica de muitos, eles podem confundir outras pessoas, produzir uma incerteza intelectual quanto à sua condição de criaturas de ficção. Segundo Freud, todos esses temas dizem respeito ao fenômeno do "duplo", que aparece em praticamente todas as narrativas, desde os mitos aos contos populares, na literatura, no cinema etc. Assim, nas narrativas, temos de considerar alguns personagens conjuntamente, porque são semelhantes e/ou porque apresentam funções complementares. Não restam dúvidas de que o avatar é um "duplo técnico", mas também um "estranho" do usuário humano, e, como procurei salientar, a condição de "duplo" não se confunde, de forma alguma, com uma réplica digital de uma representação de si previsível, estável, como se fosse uma totalidade. Além disso, como desenvolvi anteriormente, essa criatura "estranha" pode converter-se em uma figura familiar, até mesmo em função de suas possíveis conexões com lembranças e reminiscências do próprio usuário, que, surpreso, pode um dia constatar ou dar-se conta de que seu próprio avatar pode lembrar-Ihe uma pessoa com 
a qual tenha convivido na infância, alguém por quem nutriu algum tipo de sentimento especial ou mesmo teve algum tipo de envolvimento forte. São muitas as situações e razões pelas quais os usuários podem encantar-se com ou mesmo sentir medo e terror de suas criaturas.

\section{CONSIDERAÇÕES FINAIS}

o pretender fazer uma discussão sobre as relações entre usuários e seus avatares no
mundo virtual Second Life, tive como objetivo refletir sobre a existência da possibilidade cada vez mais presente de podermos habitar e viver vidas alternativas, específicas, a partir da tecnologia digital, por meio de avatares em um ambiente imersivo. Não é a mesma experiência de um robô ou de um ciborgue, mas guarda com eles o fato de escaparmos de nossa condição exclusivamente biológica e orgânica. No entanto, ao realizar essa investigação e deparar-me com essas criaturas chamadas avatares, percebi que não podem ser consideradas uma extensão, uma continuidade e muito menos uma metáfora icônica desses humanos, mas alguma coisa que excede essa condição. Nesse sentido, a criatura não pode ser pensada como uma representação estável, unívoca da "pessoa" que se conecta a ela, pois tem uma resiliência em razão de sua condição e seu modo próprio de existência como um objeto técnico gerado nas entranhas de um sistema. Embora seja objeto de um processo de singularização contínua, em função dos diferentes projetos, desejos e fantasias de seu usuário humano, nem sempre essa domesticação ou humanização do avatar acontece, mas ocorre exatamente o contrário. Dessa forma, mesmo que existam continuidades e convergências, elas não ocorrem de forma previsível e controlável como a personagem de um jogo, porque, em última instância, em função de seu caráter imersivo, ele é um ambiente intradiegético e, nesse sentido, haverá sempre uma fratura ou um deslizamento que favorece a produção da diferença e do estranho. Portanto, independentemente das intenções de se fazer uma cópia de si, o próprio processo de singularização afasta essa possibilidade e acaba impondo uma criatura que pode "ostentar" "mostrar" outras possibilidades inesperadas, que certamente causarão estranheza, mas que não deixarão de ser também familiares e encantadoras.

A partir dessa ambiguidade, liminaridade estranho/familiar, considerada por mim como algo rotineiro e constitutivo das relações sociais nessa plataforma, procurei fazer reflexões a partir de Freud, sem a pretensão de realizar uma psicanálise dos ambientes imersivos ou de seus frequentadores, menos ainda patologizar essas relações entre os usuários e seus avatares. Ao contrário, procurei demonstrar como a emergência desses territórios ou ambientes imersivos digitais torna-se propícia ao acolhimento e à objetivação de material subjetivo, que de modo algum se desloca para lá completamente sob o signo da "vontade livre", consciente 
e racional dos humanos. Embora escolhas e decisões sejam tomadas pelos usuários durante o processo de singularização de seus próprios avatares, considero que essas singularizações são realizadas quando eles já se encontram afetados pelo ambiente digital, ao mesmo tempo que continuam sob a influência dos afetos que trazem de suas RL. $O$ resultado desse encontro não é uma soma zero ou uma mistura coalescente. Nesse sentido, ao recorrer a Freud, meu intento foi relacionar seu artigo sobre o "estranho" e o fenômeno do "duplo" com esse material literário citado anteriormente sobre o "maravilhoso", o "prodigioso" e o "monstro". 0 fato de 0 artigo de Freud também fazer referências à literatura vem ao encontro de meus argumentos. Do ponto de vista etnográfico, é possível sustentar que as premissas literárias e estéticas românticas encontram-se muito presentes no SL, e, como essas premissas também influenciaram a própria teoria antropológica e a própria psicanálise, acredito que elas possam dar sustentação às reflexões que venho desenvolvendo sobre esse aspecto pouco investigado que são as relações entre humanos e suas criaturas digitais como imagens de si, mas também heterônimos, portanto estranhos. Em termos desse mundo virtual, quanto maior o enraizamento nessa plataforma, mais esse fraturamento e o deslocamento de porções de nosso material subjetivo ocorrem, fato que coloca em xeque nossas próprias "representações integradas e coerentes de si". Como afirmou Sherry Turkle (1996: 11), "in the culture of simulation, we aren't alone with the self but with many others — some of whom are our own avatars". 19 Para a autora, esses múltiplos "eus" seria uma forma de experimentarmos "um momento histórico liminar, quando o velho está começando a morrer e o novo ainda não chegou" (Turkle, 1996: 2). Esses "outros" objetificados em nossos próprios avatares seriam também os "duplos" de que fala Freud, e, nesse sentido, afasto-me de uma interpretação do avatar e de seu processo de singularização como totalmente consciente e controlado por seu humano, respectivamente.

Imaginação, literatura de horror, romances góticos, roteiros e filmes de sci-fi e psicanálise à parte, como antropóloga, eu sabia que era necessário chegar, em termos etnográficos, 0 mais próximo possível da experiência que procura situar os avatares menos como "meios" el ou meros "suportes" que são conectados por um sujeito humano que vai controlar um "objeto técnico" e desconsiderar a possibilidade inversa. Supondo que a criatura também tem agência sobre seu humano, era preciso compreender como se dava a construção desse híbrido, que não se trata exatamente de uma mistura, mas supõe o "estranho", no sentido da diferença, para não cair, eu mesma, em uma postura ingênua do conceito de híbrido. Desse modo, era importante "estar lá" e usar minha condição de residente para observar que existe uma lógica própria desse mundo, e que o investimento feito sobre o avatar faz sentido, bem como a proeminência adquirida por ele, justamente para promover essa diferença como condição necessária para a existência desse mundo virtual. 


\section{NOTAS}

1 Um primeiro contato com esse mundo virtual pode ser feito acessando a página oficial do Second Life, em: $<$ https://secondlife.com/?lang=pt-BR $>$. No final da página principal, há um vídeo que dá uma ideia do visual desse ambiente, colocando em evidência a questão a ser tratada no presente artigo. 0 vídeo também está disponível em: <https://www.youtube.com/watch?time_continue=15\&v=3-LB-Fellc4\&feature=emb_logo $>$.

2 Link para acessar o blog: <http://nwn.blogs.com/>. Acesso em: 25 jul. 2019.

3 Disponível em: <http://g1.globo.com/Noticias/Tecnologia/0,MUL356692-6174,00-PARA+JORNALISTA+VIRTUAL+SECOND+LIFE+NAO+MORREU.html>. Acesso em: 25 jul. 2019.

4 As configurações do equipamento podem ser variadas, porém ele precisa ter bastante memória RAM e uma boa placa de vídeo, além de estar conectado a uma internet com alta velocidade.

5 Veja-se a discussão proposta por Santos (2011) em O Second Life como plataforma para micromundos físicos para o ensino de física, quando denomina essa física "surreal". Meu argumento é de que essa "surrealidade" é um dos fatores que conferem o efeito "maravilhoso" e que não deixam de afetar os humanos que interagem nesse mundo por meio de seus avatares.

6 Um acessório muito importante dos avatares são os huds (heads up displays), com scripts de movimentos corporais. Um hud completo tem uma variedade grande de movimentos corporais subdivididos em: stand, walk, seat, run, jump, dance, fly e outros, que conferem um realismo impressionante.

7 Aprender a andar no SL constitui um aprendizado importante e difícil no início.

80 trabalho de Meudal versa sobre a adaptação para o cinema do livro de Lewis Carroll feita pelo diretor tcheco Jan Svankmajer (1988), conforme é mostrado no trailer oficial acessível no YouTube, o SL pode ser experimentado como um "país das maravilhas". Assim como acontece com Alice, personagem de Lewis Carroll, os recém-chegados surpreendem-se com o mundo que encontram.

9 O SL não é um game, como WoW (World of Warcraft), mas se insere na categoria de um MMORPG (Multi Massive Online Role-Playing Game), portanto um mundo virtual aberto, no qual usuários/avatares, procedentes de vários países, interagem na mesma plataforma.

10 Cujos valores chegam a ser da ordem de 3,2 bilhões USD, com 57 milhões de contas criadas e um total de 482 anos em que seus usuários mantiveram-se logados, tudo isso ao longo de seus 15 anos de existência, completados em junho de 2018, de acordo com dados de 2018. Disponível em: <http://techtrends.tech/ tech-trends/infographic-15-years-of-second-life/>. Acesso em: 29 jul. 2018.

11 Segundo Gell, "o objeto de arte personifica os processos técnicos, e aí reside seu poder de fascinação; a tecnologia do encanto fundada no encanto da tecnologia" (Gell, 2005: 41). Não por acaso, o SL atrai artistas e designers. São conhecidas as instalações feitas por estes artistas. Um dos casos mais famosos é o do artista estadunidense, AMRadio que por vários anos fez muitas instalações no SL, tendo sido tema de artigos e capas de revistas de arte nos Estados Unidos. A esse respeito ver: https://www.youtube.com/watch?v=_4AQAxhDRGc

12 Como argumentamos neste artigo, o SL permite e facilita "experiências de si" divergentes e dissidentes, além de alternativas. Não há obrigatoriedade jurídica ou moral do usuário se apresentar no SL com sua identidade civil offline. Esta pode ser mantida no mais completo anonimato. Em resumo, não existem perfis fakes no SL. Todos são considerados verdadeiros. Essa discussão não se coloca nesses termos - se um avatar é mais verdadeiro que outro, mesmo sendo de um mesmo usuário. 
13 "Não nos envolvemos em mobilidade existencial para experimentar a mobilidade física. 0 contrário é verdade: envolvemo-nos em algum tipo de mobilidade física que nos define como migrantes, porque sentimos que outro espaço geográfico é um ponto de partida melhor para nosso eu existencial."

14 "Ilhas" é o termo para se referir à unidade mínima de território no SL. Elas têm uma medida-padrão, podem ser divididas em terrenos, podem ter as mais diferentes formas, com diferentes topografias, acidentes geográficos, tudo isso criado pelos usuários junto ao seu avatar (este é quem tem as ferramentas que permitem fazer as modificações). Ver vídeo disponível em: <https://www.youtube.com/watch?v=Gbu2HN_aY7w>. Acesso em: 15 dez. 2019.

15 É importante frisar que o usuário interage com seu próprio avatar e com os demais. Como residente, ambos, usuário e avatar, não formam um bloco monolítico. Como disse, o avatar permanece com sua diferença.

16 As exigências de cuidados, singularizações e modificações criaram um mercado amplo e sofisticado de acessórios para avatares. Em artigo publicado, descrevi com detalhes essas modificações (Gomes 2015: 97-123).

17 Um usuário pode ter mais de uma conta, ou seja, mais de um avatar, podendo desenvolver várias vidas com cada um deles. Esses outros avatares são chamados alternativos e podem servir para diferentes finalidades. É praticamente certo que todo residente tenha pelo menos mais de um avatar. A própria Linden Lab tem conhecimento dessa prática e a autoriza.

18 Em sua conhecida ópera fantástica intitulada "Os contos de Hoffmann", Jacques Offenbach, compositor francês (1819-1880) dedicou uma área à boneca Olimpia, a mesma que, no conto de Hoffmann é "confundida" com uma pessoa pelo personagem Nathanael. Ver https://www.youtube.com/watch?v=mVUpKIFHqZk.

19 "Na cultura da simulação, não estamos sozinhos com o self, mas em companhia de muitos outros alguns dos quais são nossos próprios avatares."

\section{REFERÊNCIAS BIBLIOGRÁFICAS}

AM Radio@ The Far Away in Second Life. https://www.youtube.com/watch?v=_4AQAxhDRGc

APPADURAl, A. A vida social das coisas. Niterói: Eduff, 2008.

BOLOGNA, C. Monstro. In: ROMANO, R. (Org.). Enciclopedia Einaudi: vida/morte, tradições, geraç̧ões. Lisboa: Imprensa Nacional/Casa da Moeda, 1997. v. 36, p. 315-339.

CARROLL, L. Alice. Rio de Janeiro: Zahar, 2010. (Coleção Clássicos Zahar).

DELEUZE, G. Diferença e repetição. Rio de Janeiro: Graal, 1988.

FOUCAULT, M. De espaços outros. Estudos avançados: Revista do Instituto de Estudos Avançados da Universidade de São Paulo: Scielo, 2013, 27 (79), p.113-122. Disponível em: http://www.scielo.br/pdf/ea/v27n79a08.pdf

FREUD, S. 0 inquietante. In: Obras completas. São Paulo: Companhia das Letras, 2010. v. 14, p. 200-228.

GELL, A. "A tecnologia do encanto e o encanto da tecnologia". Concinnitas, vol. 1, n. 8, p. 40-63, 2005. 
GOMES, L. G. "Os modos de existência" de um avatar: imagem, inventário e perfil. Vivência: Revista de Antropologia, v. 45, n. 1, p. 97-123, 2015. Disponivel em: <https://periodicos.ufrn.br/vivencia/article/view/8254>. Acesso em: 15 dez. 2019.

GOMES, L. G. \& LEITÃO, D. K. "Estar e não estar lá, eis a questão: pesquisa etnográfica no Second Life". Cronos. Revista Pós-Graduação em Ciências Sociais, v. 1, n. 8, p. 23-38.

https://periódicos.ufrn.br/cronos/article/view/3159/2881.

HAGE, G. A not so multi-sited ethnography of a not so imagined community. Sage Journals, v. 5, n. 4, p. 463-475, 2005. Disponível em: <http://ant.sagepub.com>. Acesso em: 15 dez. 2019.

HARAWAY, D. Manifesto ciborgue: ciência, tecnologia e feminismo-socialista no final do século XX. In: TADEU, T. (Org.). Antropologia do ciborgue: as vertigens do pós-humano. São Paulo: Autêntica, 2000. p. 34-119.

HOFFMANN, E. T. A. "The sand man". In: The best tales of Hoffmann. New York: Dover Publications, 1967, p. 183-214.

KAFKA, F. A metamorfose. São Paulo: Companhia das Letras, 1998.

KAPPLER, C. Monstros, demônios e encantamentos no fim da Idade Média. São Paulo: Martins Fontes, 1994.

LATOUR, B. Reagregando o social: uma introdução à teoria do ator-rede. Salvador: EdUFBA; Bauru: Edusc, 2012.

MAUSS, M. Esboço de uma teoria geral da magia. In: Sociologia e antropologia. São Paulo: Edusp, 1974. v. 1, p. 37-176.

MEUDAL, A.-M. Le merveilleux littéraire au cinéma: Alice au pays des merveilles. 2005. Dissertação (Mestrado), Université du Maine, Le Mans, 2005.

NODARI, A. "A vida oblíqua": o hetairismo ontológico segundo G.H. O Eixo e a Roda: Revista de Literatura Brasileira, Belo Horizonte, v. 24, n. 1, p. 139-154, 2015.

RAMOS, J. Subjetivação e poder no ciberespaço: da experimentação à convergência identitária na era das redes sociais. Vivência: Revista de Antropologia, v. 45, n. 1, p. 57-75, 2015.

ROSE, N. Inventando nossos selfs: psicologia, poder e subjetividade. Petrópolis: Vozes, 2011.

SANTOS, R. "O Second Life como plataforma para micromundos físicos para o ensino de física". Renote. Revista Novas Tecnologias na Educação, v. 9, n. 1. Disponível em https://seer.ufrgs.br/renote/article/view/21965 SVANKMAJER, J. Alice (1988). Ver https://www.youtube.com/watch?v=rYIUnhHOGAQ. Trailer oficial. Último acesso em 26/12/2019.

STEVENSON, R. L. O médico e o monstro. São Paulo: Hedra, 2012.

TURKLE, S. Sex, lies and avatars. Wired, p. 2-13, abr. 1996. 